Research Article

\title{
Biological Efficacy and Toxicological Evaluation of Ethanolic Extract of Cassia nodosa Buch.-Ham. (Leguminosae)
}

\author{
Gameli Afu, ${ }^{1}$ Michael Konney Laryea, ${ }^{1}$ and Lawrence Sheringham Borquaye $\mathbb{D}^{1,2}$ \\ ${ }^{1}$ Department of Chemistry, Kwame Nkrumah University of Science and Technology, Kumasi, Ghana \\ ${ }^{2}$ Central Laboratory, Kwame Nkrumah University of Science and Technology, Kumasi, Ghana \\ Correspondence should be addressed to Lawrence Sheringham Borquaye; lsborquaye.sci@knust.edu.gh
}

Received 28 June 2020; Revised 31 August 2020; Accepted 11 September 2020; Published 27 September 2020

Academic Editor: Andrea Mastinu

Copyright (c) 2020 Gameli Afu et al. This is an open access article distributed under the Creative Commons Attribution License, which permits unrestricted use, distribution, and reproduction in any medium, provided the original work is properly cited.

Medicinal plants are used worldwide to treat various diseases. However, scientific validation of the therapeutic potential of most medicinal plants is absent, and little to no information on their potential toxicity exists. It is therefore important to assess the efficacy and toxicity of various medicinal plants commonly used in traditional herbal medicine. The main goal of this study was to evaluate the efficacy and toxicity of the ethanolic extract of Cassia nodosa, a plant used in the treatment of fever, cold, gastric pain, diabetes mellitus, and malaria in Ghana. The stem bark extract of Cassia nodosa was obtained by cold maceration. Following phytochemical examination via standard procedures, the extract was screened for antiplasmodial, anti-inflammatory, and antioxidant activities. The extract was also evaluated for acute oral toxicity and its toxicity to the liver and kidney of rats. Phytochemicals present in the extract included sterols, alkaloids, tannins, glycosides, and coumarins. In the in vitro antiplasmodial activity test, the Cassia nodosa extract showed moderate antiplasmodial activity with an $\mathrm{IC}_{50}$ value of $23.98 \pm 2.07 \mu \mathrm{g} / \mathrm{ml}$. An $\mathrm{ED}_{50}$ value of $8.52 \pm 2.83 \mathrm{mg} / \mathrm{kg}$ in the anti-inflammatory test indicated that the Cassia nodosa extract administered orally was very active in reducing inflammation. The total antioxidant capacity of the extract was determined to be $48.49 \pm 5.24 \mathrm{gAAE} / 100 \mathrm{~g}$ with the total phenolic content being $28.48 \pm 3.13$ (gGAE/100 g) extract. In the DPPH radical scavenging assay, the concentration required for $50 \%$ inhibition of DPPH radical was found to be $78.71 \pm 6.84 \mu \mathrm{g} / \mathrm{mL}$. There was a gradual increase in the body weight of rats in both treated and control groups during the acute toxicity test. Clinical biochemical tests did not show any significant differences between control and treated groups of animals in terms of liver and renal functions, 14 days after administration of Cassia nodosa extracts. Taken together, these results provide scientific validation for the use of the plant in traditional medicine.

\section{Introduction}

Natural product-derived therapeutics have remained the mainstay of many healthcare programs all over the world [1]. In Africa especially, plant-based herbal formulations have been used for the treatment of various symptoms and ailments and are still heavily relied upon even in present times. The World Health Organization (WHO) estimates that plant-based therapeutics support about $70 \%$ of the world's population in terms of their primary healthcare needs [2]. Herbal medicines are usually affordable and much more accessible and as such are being integrated into the formal primary healthcare pipeline of many countries [3]. The use of herbal medicines in many African countries is usually without the stringent regulations associated with orthodox medicines. As such, issues of toxicity are rarely addressed. However, reports of suspected toxicity and adverse events exist in the literature [4]. These reactions may be due to side effects, overdose, or the presence of toxic compounds in the plant extracts. Reports of renal and hepatotoxicity of herbal preparations have been on the increase [5]. Thus, toxicological evaluation of plant extracts has become necessary in current research endeavors.

In Ghana, over 1,000 plant species have been certified as being medicinal, and most of these plants are either used alone or in combination for the treatment of ailments such as malaria, gonorrhea, diabetes, hypertension, typhoid, wounds, and sexual weakness $[6,7]$. Some of these plants 
have been proven scientifically to possess activities such as antimicrobial, antidiabetic, antioxidant, antiplasmodial, and anti-inflammatory [8-11]. One such plant used in Ghana in various traditional herbal preparations is Cassia nodosa (synonym: Cassia javanica).

Cassia nodosa Buch.-Ham. is an ornamental tree in the Leguminosae family. The plant is a perennial tree with a height of 3-5 m. It is scattered in Burma, India, Bangladesh, and Pakistan. Cassia nodosa is widely cultivated all over the tropics and is naturalized in Asia, Australia, America, and tropical West Africa including Ghana [12,13]. The plant, in Ghana, can be located in Obomeng in Kwahu in the Eastern region. Traditionally, Cassia nodosa is useful because of the purgative activity of its pods and leaves. It is used to treat bites of insects, cheloid tumor, rheumatism, and ring worms. The bark of Cassia nodosa is used as one of the components in antidiabetic ayurvedic formulations. The leaves are used in preparations for the treatment of herpes simplex infection. In Ghana, Cassia nodosa is used in preparations targeted towards the cure of malaria, constipation, cold, fever, gastric pain, and diabetes mellitus [14].

Despite its widespread use, no report on the antiplasmodial activities of extracts of the plant exists in the literature. In addition, only scattered reports of the antiinflammatory and antioxidant activities as well as the toxicity of the plant extract exist [15]. This work was therefore designed to investigate the biological activities (antiplasmodial, anti-inflammatory, and antioxidant) and the toxicological profile of the stem bark ethanolic extract of Cassia nodosa. Chloroquine-sensitive Plasmodium falciparum 3D7 strain was used for the antiplasmodial assay, whereas the carrageenan-induced foot edema assay was used for the anti-inflammatory study. The antioxidant activities were tested using the phosphomolybdenum and the 2,2-diphenyl-1-picrylhydrazyl (DPPH) radical scavenging assays. The total phenolic content of the extract was also determined using the Folin-Ciocalteu method. Acute toxicity, liver and kidney function test, and behavioral changes in the murine model were used to evaluate toxicity.

\section{Experimental Methods}

2.1. Collection of Sample, Preparation, and Extraction. Stem bark samples of Cassia nodosa were collected from the Eastern Region of Ghana in November 2018. Herbarium specimen of the sample was authenticated, deposited into the Herbarium Section of the Department of Herbal Medicine, Kwame Nkrumah University of Science and Technology (KNUST). The samples were cut into very small pieces and air-dried for 28 days before milling into powder. Seven hundred grams $(700 \mathrm{~g})$ of the powdered stem bark was subjected to cold maceration in $2.5 \mathrm{~L}$ of ethanol for 72 hours with frequent agitation. The ethanolic extract obtained after filtration was concentrated under vacuum (Cole Parmer Rotary Evaporator N-1110, China) and stored at $4^{\circ} \mathrm{C}$. Table 1 provides information about the plant and its local medicinal uses in Ghana.
2.2. Phytochemical Screening. The ethanolic extract of Cassia nodosa was screened for tannins, steroids, flavonoids, alkaloids, coumarins, and glycosides using established qualitative phytochemical procedures reported elsewhere $[16,17]$. The presence of tannins was tested by adding $3 \mathrm{~mL}$ of $10 \%$ lead acetate solution to $3 \mathrm{~mL}$ of extract. Formation of a bulky white precipitate indicates the presence of tannins. To test for steroids, $5 \mathrm{ml}$ of the extract was reconstituted in chloroform. Concentrated sulphuric acid was carefully added down the side of the test tube to form a lower layer. The formation of a reddish-brown/cherry red color at the interface indicates the presence of a steroid with a triterpenoid nucleus. For the flavonoid test, a strip of filter paper was dipped into the liquid extract and dried. The filter paper strip was then exposed to ammonia solution followed by fumes of concentrated hydrochloric acid. The observation of an intense yellow coloration upon exposure to the fumes of concentrated ammonia solution and subsequent disappearance of the color upon exposure to the fumes of concentrated hydrochloric acid indicates the presence of flavonoids. The presence of alkaloids was tested by dissolving extract in ammoniacal alcohol, filtering, and evaporating to dryness. The residue was reextracted with $1 \%$ sulphuric acid and filtered, and the filtrate rendered alkaline with dilute ammonia solution. It was then shaken with chloroform; the chloroformic layer was then separated and concentrated to dryness. The residue was dissolved in $1 \%$ sulphuric acid. The observation of an orange red precipitate by the addition of one drop of Dragendorff's reagent indicates the presence of alkaloids. The test for coumarins involved dissolving the plant extract in $5 \mathrm{ml}$ of ether and evaporating to dryness. The residue obtained was dissolved in hot water and then cooled, after which $0.5 \mathrm{ml}$ of $10 \%$ ammoniacal solution was added to a portion of the dissolved residue. The occurrence of an intense bluish green fluorescence under UV light is a positive test for the presence of coumarins and their derivatives. In the test for glycosides, the extract was dissolved in $5 \mathrm{ml}$ of dilute $\mathrm{HCl}$, followed by warming on a water bath for 2 minutes. The resultant solution was filtered and rendered distinctly alkaline by adding 2-5 drops of $20 \%$ ammonium hydroxide solution. One milliliter of Fehling's A and B solution was added to the filtrate and warmed on a water bath for 2 minutes. The formation of a brick-red precipitate indicates the presence of glycosides.

\section{Bioassays}

3.1. Antiplasmodial Activity. Chloroquine-sensitive Plasmodium falciparum 3D7 strain was obtained from the Department of Immunology, Noguchi Memorial Institute for Medical Research (NMIMR), University of Ghana, and used for the in vitro antiplasmodial tests. Parasites were introduced to freshly prepared $\mathrm{O}^{+}$human erythrocytes suspended in complete parasite medium (RPMI-1640 containing $5 \mathrm{mg} / \mathrm{mL}$ AlbuMAX II, $10 \mu \mathrm{g} / \mathrm{mL}$ gentamycin, $0.2 \mu \mathrm{g} / \mathrm{mL}$ hypoxanthine, $2 \mathrm{mML}$ glutamine, $25 \mathrm{mM}$ HEPES, and $23.8 \mathrm{mM}$ $\mathrm{NaHCO}_{3}$ ), enhanced with $10 \%$ normal human serum and gassed with a gas mixture containing $2 \% \mathrm{O}_{2}, 5.5 \% \mathrm{CO}_{2}$, and $92.5 \% \mathrm{~N}_{2}$ (Air Liquide, UK). The culture was incubated at $37^{\circ} \mathrm{C}$. 
TABLE 1: Botanical name, family, local name, part used, and local indication of plant.

\begin{tabular}{lc}
\hline Botanical name & Cassia nodosa (synonym: Cassia javanica) \\
\hline Family & Leguminosae \\
Common name & Pink cassia \\
Local name & Sesa dua (twi) \\
Plant part used & Stem bark \\
Local indication & Ethanol \\
Solvent used & Constipation, cold, fever, gastric pain, malaria, and diabetes mellitus \\
Physical state & Brown crystals \\
Yield $(\%)$ & 18.97 \\
\hline
\end{tabular}

The parasite culture was maintained daily by aspirating the medium and replacing it with a fresh one [18].

A stock solution $(250 \mathrm{mg} / \mathrm{mL})$ of the extract of Cassia nodosa was prepared by dissolving in $70 \%$ ethanol. The stock was diluted to obtain six concentrations between $0.586 \mu \mathrm{g} /$ $\mathrm{mL}$ and $600 \mu \mathrm{g} / \mathrm{mL}$. Plasmodium culture was then synchronized with $5 \%$ sorbitol to obtain the ring stage of the Plasmodium falciparum required for the assay. Working solutions were prepared in complete medium. Aliquot $(50 \mu \mathrm{L})$ of plant extract was dispensed into flat-bottom 96well microtiter plate (Thermo Fisher Scientific Nunc ${ }^{\mathrm{TM}}$, USA), and $1.5 \%$ cell suspension of parasitized erythrocytes containing $0.9-1.5 \%$ parasitemia was added to each well in triplicates. Solvent controls were also incorporated into some of the wells. Artemisinin was used as standard drug. The plates were then placed in a desiccator, gassed with a special gas mixture $\left(2 \% \mathrm{O}_{2}, 5.5 \% \mathrm{CO}_{2}\right.$, and $\left.92.5 \% \mathrm{~N}_{2}\right)$, capped, and immediately transferred into an incubator set at $37^{\circ} \mathrm{C}$.

After 72 hours, the assay was terminated, and thin smears were made on glass slides from each duplicated well. This was then fixed in methanol for 10 seconds and allowed to dry. The slides were then placed in staining jars containing 10\% Giemsa stain (Fluka Chemicals, UK) for 15 minutes. They were then washed, dried, and examined using $100 \times$ magnification oil immersion objective lens of light microscope (Leica 1349522X, USA). Blood films were carefully reviewed for the presence of any blood parasites. The number of infected erythrocytes in a given grid area was counted. These included those with rings, trophozoites, and schizonts. A minimum of 1000 RBCs were counted for each smear [19]. The percentage of parasitemia was computed using the expression as follows:

$$
\% \text { paracitemia }=\frac{\text { number of infected } \mathrm{RBCs}}{\text { total number of RBCs }} \times 100 .
$$

$\mathrm{IC}_{50}$ was then computed from plotted dose-response curves deduced from the data. Microsoft Excel and GraphPad Prism software were used for all data and statistical analysis.

3.2. Effect of Extract on Erythrocytes. To assess the effect of the extract on erythrocytes, $200 \mu \mathrm{L}$ of erythrocytes was incubated with $600 \mu \mathrm{g} / \mathrm{mL}$ of the extract, which represented the highest extract concentration used in the antiplasmodial assay. A drug control group with artemisinin was also prepared. Experimental conditions were kept same as that for the antiplasmodial assay. After 72 hours of incubation, the reaction was terminated. Thin blood smears were prepared and fixed with methanol on glass slides and air-dried. Smears were stained with Giemsa stain, and morphological variations in erythrocytes, if any, were observed under a light microscope fitted with a camera (Leica 1349522X, USA). These morphological findings were compared with the normal erythrocytes of the control group [20].

\section{Anti-Inflammation Assay}

4.1. Animals Used. The cockerels (Gallus gallus, strain Shaver 5790) used in the study were 1-day posthatched obtained from Akate Farms in Kumasi. They were maintained in an animal house at the Department of Pharmacology, KNUST. The cockerels were kept in stainless steel cages with dimensions of $34 \times 57 \times 18 \mathrm{~cm}^{3}$ and at a population density of 12-13 chicks per cage. By means of water troughs and 1-quart gravity-fed feeders, the cockerel had free access to water and food. The cockerels were acclimatized for 7 days before being used for the assay. Chicks were grouped into five (5) sample sizes throughout the studies. The National Institute of Health guidelines for the care and use of laboratory animals were used as a guide in handling of chicks.

4.2. Carrageenan-Induced Foot Edema in Chicks. The antiinflammatory activities of Cassia nodosa extract was studied in the cockerels using the carrageenan-induced foot edema assay with little modifications. Diclofenac was used as reference standard. The curative method was employed to evaluate the anti-inflammatory activity. Vernier calipers were used to measure dorsoventral foot sizes. All extracts were prepared in normal saline to enhance bioavailability. The reference drug was also prepared in normal saline solution. The drugs and extracts were prepared in a manner that the volume to be administered was based on the weight of each chick. Groups of 5 chicks were treated with different concentrations of $30 \mathrm{mg} / \mathrm{kg}, 100 \mathrm{mg} / \mathrm{kg}$, and $300 \mathrm{mg} / \mathrm{kg}$ of the extract orally 90 minutes after right foot subplantar injection of $1 \mathrm{ml}$ of $1 \% \mathrm{w} / \mathrm{v}$ carrageenan in normal saline solution. The reference drug diclofenac $(10,30$, and $100 \mathrm{mg} /$ $\mathrm{kg}$ ) was also administered via intraperitoneal injection to another group, 90 minutes after the carrageenan administration. After the carrageenan injection, the dorsoventral foot sizes were measured at hourly intervals for up to six (6) 
hours. Another group of chicks received only normal saline as treatment, and this served as the negative control [21, 22].

4.3. Data Analysis. Percentage increase in foot size over the five hours following treatment with Cassia nodosa extract and the reference drug was calculated using the following formula:

$$
\text { percentage increase in foot size }=\frac{F_{t}-F_{0}}{F_{0}} \times 100,
$$

where $F_{t}$ is the foot volume at time $t$ posttreatment and $F_{o}$ is the foot volume measured at time $o$ before the challenge. Various groups were averaged.

Total foot volume for each treatment was calculated in arbitrary unit as the area under the curve (AUC) for such treatment, and the percentage inhibition of edema was determined for the treatment groups using the following formula:

$$
\% \text { inhibition of edema }=\frac{\mathrm{AUC}_{\mathrm{control}}-\mathrm{AUC}_{\text {treatment }}}{\mathrm{AUC}_{\text {control }}} \times 100 \text {. }
$$

Differences in area under the curve (AUC) were analyzed by ANOVA and then followed by Dunnett's test. GraphPad Prism version 5 was used for all statistical analyses. $\mathrm{ED}_{50}$ values (dose responsible for $50 \%$ of maximal effect) for each extract were determined using an iterative computer least square method with the following nonlinear regression (three-parameter logistics) equation:

$$
Y=\frac{a+(b-a)}{1+10^{(\log E D 50-X)}}
$$

where $X$ is the logarithm of dose and $Y$ is the response. $Y$ starts at $a$ (the bottom) and goes to $b$ (the top) with a sigmoid shape. GraphPad Prism for windows version 10.0 (GraphPad Software, San Diego, CA, USA) was used for all statistical analyses and $\mathrm{ED}_{50}$ determinations. $P<0.05$ was considered statistically significant.

\section{Antioxidant Activities}

5.1. Phosphomolybdenum Method. The reagent solution for the assay consisted of $28 \mathrm{mM}$ trisodium phosphate, $0.6 \mathrm{M}$ sulphuric acid, and $4 \mathrm{mM}$ ammonium molybdate. Six milliliters $(6 \mathrm{~mL})$ each of different concentrations $(50,100,150$, 200 , and $250 \mathrm{ppm}$ ) of the extracts in $1 \%$ DMSO was added to $6 \mathrm{~mL}$ of the reagent solution in centrifuge tubes and incubated at $95^{\circ} \mathrm{C}$ for 90 minutes. After incubation, reaction mixtures were allowed to cool at room temperature for 15 minutes, after which absorbance was measured at $695 \mathrm{~nm}$. As a negative control, a blank determination was prepared by adding $6 \mathrm{~mL}$ of $1 \% \mathrm{DMSO}$ to $6 \mathrm{~mL}$ of the reagent solution and taken through same experimental procedures as the test extracts. Five different concentrations of reference drug ascorbic acid $(20,40,60,80$, and $100 \mathrm{ppm})$ were also prepared and taken through same procedure as the test samples. The ascorbic acid was used to obtain a calibration curve. The total antioxidant capacity (ascorbic acid equivalence) of the extract was then determined as the number of ppm of ascorbic acid per 100 gram of the crude extract. Antioxidant capacity was expressed as equivalents of ascorbic acid with the following equation:

$$
\mathrm{TAC}=\frac{\mathrm{C} \times \mathrm{V}}{\mathrm{M}} \times 100,
$$

where TAC is the total antioxidant capacity in gAAE/100 $\mathrm{g}$ of the test sample, $C$ is the concentration of ascorbic acid (ppm), $V$ is the volume of the reaction mixture, and $M$ is the mass of the extract in the reaction mixture [23].

5.2. DPPH Assay. 2,2-Diphenyl-1-picrylhydrazyl (DPPH) free radical scavenging activity assay was used to evaluate the radical scavenging activity of the extract. The DPPH reagent $(0.1 \mathrm{mM})$ was prepared in methanol, and $250 \mu \mathrm{L}$ aliquots were added to $25 \mu \mathrm{L}$ of different concentrations of extract in a microtiter plate. The mixture was incubated in the dark at room temperature $\left(27^{\circ} \mathrm{C}\right)$ for 30 minutes, and absorbance readings were taken at $517 \mathrm{~nm}$. Different concentrations of the ascorbic acid were treated under the same condition and served at the control. The radical scavenging activity of extract was expressed as

$$
\operatorname{activity}(\%)=\frac{A_{O}-A}{A_{O}} \times 100 \text {, }
$$

where $A$ is the absorbance value of the mixture of DPPH and the test samples and $A_{\mathrm{o}}$ is the absorbance value of DPPH. The $\mathrm{IC}_{50}$ (concentration required for $50 \%$ inhibition) values were obtained from a dose-response curve obtained by plotting percentage scavenged ( $\%$ activity) against extract concentrations [24].

5.3. Total Phenolic Content. Spectrophotometric method was used to determine the concentration of the phenolic compounds in the extracts. Three microliters $(3 \mu \mathrm{L})$ of the extract at different concentrations was added to $3 \mu \mathrm{L}$ of $7.5 \%$ $\mathrm{Na}_{2} \mathrm{CO}_{3}$ solution and $3 \mu \mathrm{L}$ of 10 -fold dilute Folin-Ciocalteu (FC) reagent in a test tube. The test tubes were then covered with aluminum foil and allowed to stand for 30 minutes at room temperature. Different concentrations of gallic acid solutions were prepared, and $3 \mu \mathrm{L}$ of each concentration was added to $3 \mu \mathrm{L}$ of the $\mathrm{FC}$ reagent and $7.5 \% \mathrm{Na}_{2} \mathrm{CO}_{3}$ solution. This served as the positive control. Absorbance of the resulting solutions was taken at $760 \mathrm{~nm}$. The phenolic content was obtained from the gallic acid calibration curve and expressed as grams of gallic acid equivalent per gram of dry weight of sample (gGAE/100 g) [23].

\section{Toxicity Studies}

6.1. Animals. The guidelines for testing of chemicals $[25,26]$ of the Organization for Economic Cooperation and Development (OECD) were used. Female Wistar albino rats (8-10-week-old and pathogen-free) were used for the study. The female Wistar albino rats were obtained from the Animal Unit of the Centre for Plant Medicine Research 
(CPMR), Mampong-Akuapem, in the Eastern Region of Ghana. The rats used were nulliparous or nonpregnant. The animals were acclimated to laboratory conditions for 7 days before experiments were carried out. Standard cages under standard conditions, i.e., at a temperature of $25 \pm 3^{\circ} \mathrm{C}$, with a 12-hour dark/light cycle were used to house the animals. The animals had free access to standard water and diet [27].

6.2. Acute Toxicity and Behavioral Changes. Twenty female Wistar albino rats were fasted overnight but allowed free access to water. They were randomly divided into four groups of 5 animals in each cage. To a control group, dimethyl sulfoxide (DMSO, $1 \%$ in distilled water) was administered, whereas the 3 other groups received Cassia nodosa extract at doses of $50 \mathrm{mg} / \mathrm{kg}, 300 \mathrm{mg} / \mathrm{kg}$, and $2,000 \mathrm{mg} / \mathrm{kg}$, as prescribed by OECD. The animals were observed immediately after extract or vehicle administration and at 30 minutes, 60 minutes, 4 hours, and 24 hours postextract or vehicle administration and then once a day for the next 14 days for any signs or symptoms of toxicity. Their autonomic (salivation, defecation, perspiration, piloerection, and lacrimation), behavioral (walking patterns, grooming, and rearing), and neurological (drowsiness, convulsion, tremors, and gait) profiles were noted. Also, weight loss (daily) was monitored. Final weights of rats were taken on day 15th, followed by clinical physical examinations. At the end of the study, records were taken on the survived rats [28].

6.3. Serum Analysis. The rats were anesthetized (3\% pentobarbital sodium; dose: $50 \mathrm{mg} / \mathrm{kg}$ ), and blood $(2-3 \mathrm{~mL})$ was collected from their chest cavity into gel tubes with no anticoagulants. Blood was centrifuged at $3,000 \mathrm{rpm}$ for 10 minutes to obtain sera. Blood chemistry (urea, creatinine, alanine transaminase (ALT), alkaline phosphatase (ALP), aspartate transaminase (AST), total bilirubin (TB), indirect bilirubin (IB), and direct bilirubin (DB)) was studied in the sera to test hepatic and renal functions. Serum analyses were carried out using the Automated Clinical Chemistry Analyzer (Le Scientific Medfuture LCC, USA) following standard procedures [29].

6.4. Statistical Analysis. The results of the serum analyses were expressed as mean \pm SEM of three replicates tests. All the grouped data were statistically evaluated by one-way analysis of variance (ANOVA) followed by Dunnett's post hoc test $(P$ values $<0.05$ were considered to be statistically significant). Body weight measurements were expressed as mean \pm SEM for 5 animals in each group.

\section{Results}

7.1. Extraction and Phytochemical Screening. The herbarium specimen of Cassia nodosa was authenticated at the Department of Herbal Medicine, KNUST, and a voucher number (KNUST/HM1/2018/SB009) was assigned. Cold maceration of the stem bark sample of Cassia nodosa with ethanol afforded a brown solid in about $19 \%$ yield (Table 1 ). Biological activities of most medicinal plants are due to the presence of different phytochemicals. Phytochemical screening of the crude ethanolic extract of the stem bark of Cassia nodosa indicated that alkaloids, tannins, and glycosides were moderately present. Sterols and coumarins were also present. Flavonoids were however absent in the extract. Table 2 summarizes the results of the phytochemical analyses.

7.2. In Vitro Antiplasmodial Activity. Cassia nodosa extract showed appreciable antiplasmodial activity with an $\mathrm{IC}_{50}$ value of $23.98 \pm 2.07 \mu \mathrm{g} / \mathrm{ml}$, as shown in Table 3 . The artemisinin standard showed antiplasmodial activity with an $\mathrm{IC}_{50}$ of $0.014 \mu \mathrm{g} / \mathrm{mL}$ [30]. Classify the antiplasmodial activity of plant extracts as follows: $\mathrm{IC}_{50}<5 \mu \mathrm{g} / \mathrm{mL}$ (very active), $5 \mu \mathrm{g} / \mathrm{mL}<\mathrm{IC}_{50}<10 \mu \mathrm{g} / \mathrm{mL}$ (active), $10 \mu \mathrm{g} / \mathrm{mL}<\mathrm{IC}_{50}<25 \mu \mathrm{g} /$ $\mathrm{mL}$ (moderately active), $25 \mu \mathrm{g} / \mathrm{mL}<\mathrm{IC}_{50}<50 \mu \mathrm{g} / \mathrm{mL}$ (weakly active), and $\mathrm{IC}_{50}>50 \mu \mathrm{g} / \mathrm{mL}$ (inactive) [30]. Based on this classification, the ethanolic extract of Cassia nodosa can be described as possessing moderate antiplasmodial activity. Incubation of infected red blood cells with Cassia nodosa extracts resulted in no noticeable changes in the morphology of the red blood cells even after 72 hours, indicating that these extracts are not harmful to the red blood cells (Figure 1).

7.3. Inhibition of Carrageenan-Induced Foot Edema in Chicks. The time course curve in Figure 2 shows the change in foot volume of the chicks from induction of inflammation to a couple of hours postintervention. The foot volume of chicks increased from carrageenan administration all the way to the $90^{\text {th }}$ minute where maximum foot volume was recorded. At this point, drug or extract was administered. Negative control group received only saline. A reduction in foot volume was observed for all groups. However, a noticeable reduction in foot volume was observed for groups that received diclofenac (Figure 2(c)) and Cassia nodosa extract (Figure 2(a)). The area under each curve, which represents the total edema, was computed and plotted as bar charts (Figures 2(b) and 2(d)). A dose-dependent relationship is observed for both standard diclofenac and Cassia nodosa extract groups. The dose-dependent effect was also evident in the \% inhibitions of all the Cassia nodosa extract (Figures 2(b) and 2(d)).

The dosage required to reduce edema by $50 \%\left(\mathrm{ED}_{50}\right)$ was $8.52 \pm 2.83 \mathrm{mg} / \mathrm{kg}$ for Cassia nodosa extract and $10.08 \pm 1.23 \mathrm{mg} / \mathrm{kg}$ for the standard diclofenac treatment. However, no significant difference existed between these two groups (Table 3).

7.4. Antioxidant Activities. The antioxidant activities of the extract of Cassia nodosa were studied by the phosphomolybdenum (PM) and DPPH radical scavenging assays. The total antioxidant capacity (TAC) obtained from the PM assay was $48.49 \pm 5.24 \mathrm{~g} / 100 \mathrm{~g}$ AAE. From the DPPH assay, the concentration of the extract required to scavenge $50 \%$ of 
TABle 2: Phytoconstituents in the stem bark extract of Cassia nodosa.

\begin{tabular}{lc}
\hline Phytochemical test & Result \\
\hline Flavonoids & - \\
Sterols & + \\
Alkaloids & ++ \\
Tannins & ++ \\
Glycosides & ++ \\
Coumarins & + \\
\hline
\end{tabular}

-, absent; +, present; ++, strongly present.

Table 3: Antiplasmodial and anti-inflammatory activities of Cassia nodosa extract.

\begin{tabular}{lcc}
\hline Extract or standard drug & Antiplasmodial activity $\left(\mathrm{IC}_{50}\right.$ in $\left.\mu \mathrm{g} / \mathrm{mL}\right)$ & Anti-inflammatory activity $(\mathrm{ED} 50$ in $\mathrm{mg} / \mathrm{kg})$ \\
\hline Cassia nodosa & $23.98 \pm 2.07^{*}$ & $8.52 \pm 2.83^{\#}$ \\
Artemisinin & $0.014 \pm 0.005$ & $\mathrm{NA}$ \\
Diclofenac & NA & $10.08 \pm 1.23^{\#}$ \\
\hline
\end{tabular}

*Antiplasmodial activity was described as moderate based on classification by Ramanandraibe and coworkers [30]. ${ }^{*}$ No significant difference between values $(P<0.05)$. NA, not applicable (test was not performed). Results were expressed as mean \pm SEM of 3 replicate experiments.
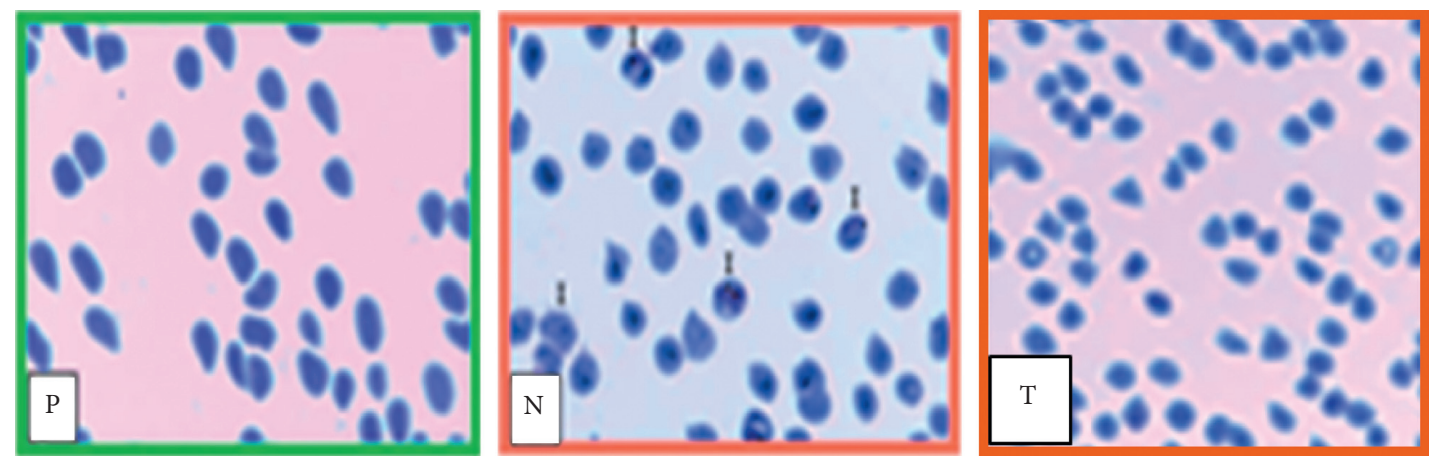

FIGURE 1: Micrographs of Plasmodium falciparum-infected red blood cells after extract or standard drug treatment for 72 hours and staining with Giemsa. P, positive control (artemisinin treated); N, negative control (untreated); T, Cassia nodosa treated. Infected red blood cells are denoted as "I" in erythrocytes.

the DPPH radicals $\left(\mathrm{IC}_{50}\right)$ was estimated to be $78.71 \pm 6.84 \mu \mathrm{g} / \mathrm{mL}$. In the DPPH assay, the standard ascorbic acid yielded an $\mathrm{IC}_{50}$ of $20.71 \pm 2.39 \mu \mathrm{g} / \mathrm{mL}$. The total phenolic content (TPC) of the extract was also determined since phenolic compounds have been suggested as potent antioxidants. The TPC of the Cassia nodosa extract was determined to be $28.48 \pm 3.13 \mathrm{~g} \mathrm{GAE} / 100 \mathrm{~g}$, indicating that the phenolic content in the extract was about one-fourth that of pure gallic acid. Table 4 summarizes the results of the antioxidant activity assays.

\subsection{Toxicological Evaluations}

7.5.1. Acute Toxicity and Behavioral Changes. To evaluate acute toxicity, 50, 300, and $2000 \mathrm{mg} / \mathrm{kg}$ of Cassia nodosa extracts were administered to groups of Wistar female albino rats. Control group received only saline. Rats were then studied for 14 days. All animals did not manifest any visible signs of toxicity at all doses studied. No deaths were also recorded. No tremors, diarrhea convulsion, and salivation signs were observed. Morphological characteristics (skin, nose, eyes, and fur) were observed to be normal, whereas unusual behaviors such as walking backward and self-mutilation were absent. Grip strength, reactivity to handling or sensory stimuli, gait, and posture were all normal. Thus, clinical observations did not show any significant differences between treated groups and the control.

The body weight of the treated and control rats gradually increased during the duration of the study (Figure 3). The average body weight of control rats at the beginning of the experiment was $120.65 \pm 9.85 \mathrm{~g}$. This increased to $164.4 \pm 16.68 \mathrm{~g}$ after 14 days. On average, the body weight gain for the control rats group was $43.75 \mathrm{~g}$. For the treatment groups, the initial average body weights of rats administered with $50 \mathrm{mg} / \mathrm{kg}, 300 \mathrm{mg} / \mathrm{kg}$, and $2000 \mathrm{mg} / \mathrm{kg}$ doses were $94.72 \pm 9.73 \mathrm{~g}, 121.4 \pm 15.64$, and $163.04 \pm 8.38$, respectively. 


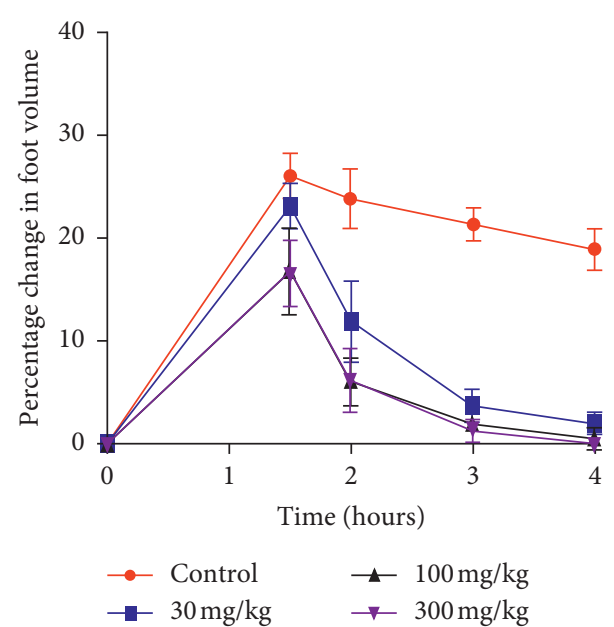

(a)

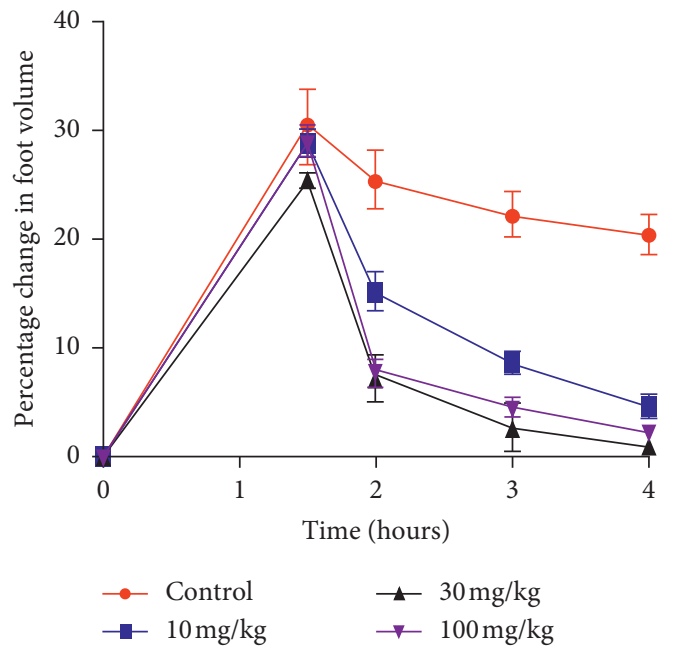

(c)

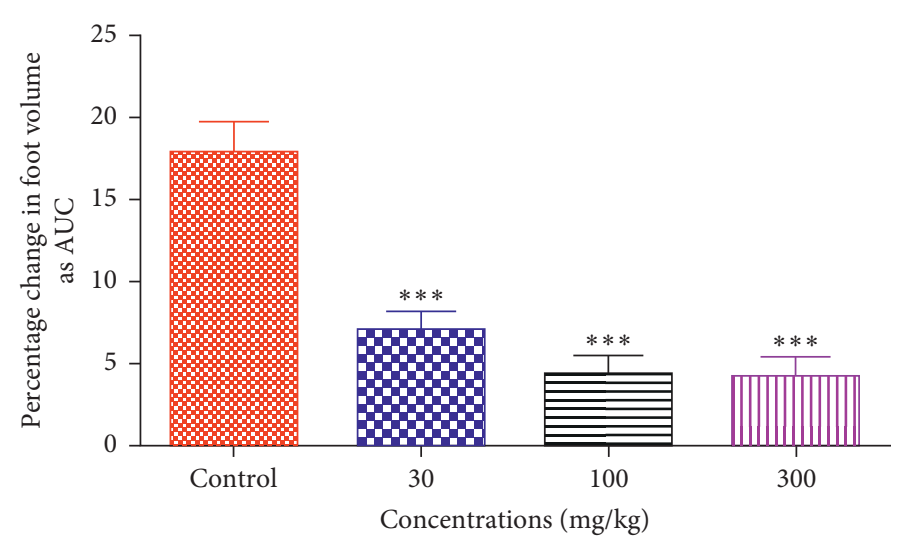

(b)

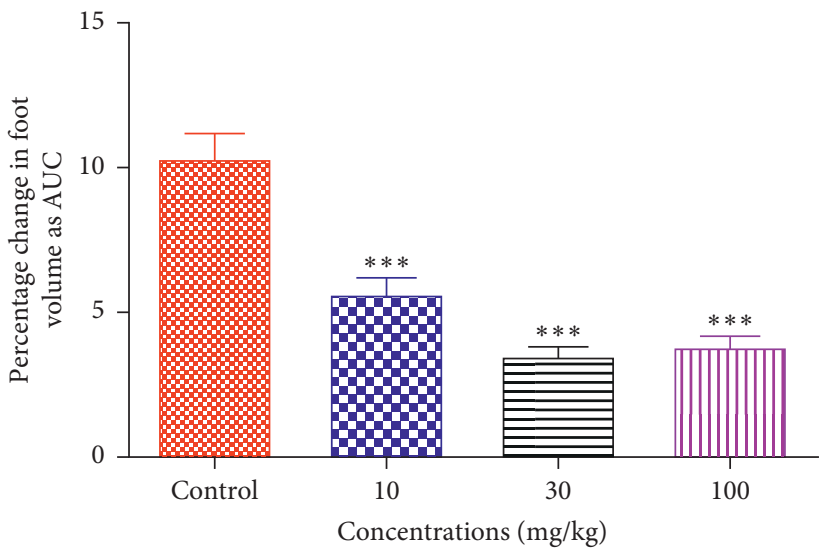

(d)

FIGURE 2: Effects of varying concentrations of Cassia nodosa ethanolic extract (a) and diclofenac (c) on carrageenan-induced edema in chick foot expressed on a time course curve, and the total edema response was expressed as area under the curve for Cassia nodosa ethanolic extract (b) and diclofenac (d). All values represent mean \pm SEM for five replicates $(n=5) . P>0.05$ (ns), $P<0.05^{*}, P<0.01^{* *}$, and $P<0.001^{* * *}$, compared to control group treated with normal saline (one-way ANOVA followed by Dunnett's post hoc test).

After 14 days, the average weights recorded were $144.14 \pm 20.66, \quad 161.53 \pm 25.44 \mathrm{~g}$, and $192.72 \pm 18.30$ and $50 \mathrm{mg} / \mathrm{kg}, 300 \mathrm{mg} / \mathrm{kg}$, and $2000 \mathrm{mg} / \mathrm{kg}$ in treatment groups, respectively. The average body weight gain for rats treated at these three doses $(50 \mathrm{mg} / \mathrm{kg}, 300 \mathrm{mg} / \mathrm{kg}$, and $2000 \mathrm{mg} / \mathrm{kg}$ ) was $49.42 \mathrm{~g}, 40.13 \mathrm{~g}$, and $29.68 \mathrm{~g}$, respectively.

7.5.2. Serum Analysis. To evaluate the effect of Cassia nodosa extract on renal and hepatic function, key enzyme activities related to the proper functioning of the liver and kidney were measured. Urea and creatinine levels were used in the kidney function test, whereas alanine transaminase (ALT), alkaline phosphatase (ALP), aspartate transaminase (AST), total bilirubin (TB), indirect bilirubin (IB), and direct bilirubin (DB) were used for liver function tests. The levels of ALT, ALP, AST, TB, IB, and DB serum samples drawn from rats treated with different concentrations of extract are presented in Figure 4, whereas the levels of urea and creatinine for the same treatments are presented in Figure 5. For all parameters measured, no significant difference existed between values obtained for the treatment groups and those for the control group $(P<0.05)$.

\section{Discussion}

The stem bark of Cassia nodosa was chosen for this study primarily because of its widespread use in folkloric medicine for the treatment of various diseased conditions. Cassia nodosa is used to treat ear infection, fever, stomach aches, malaria, headache, and sores [14]. Cold maceration was chosen as the method of extraction to protect the integrity of the thermolabile active principles. Additionally, it was chosen to reflect the method used by many traditional herbal practitioners in the preparation of many herbal medications. After concentration, the extract was obtained in $18.9 \%$ yield. 
TABLE 4: Antioxidant activities of Cassia nodosa extract.

\begin{tabular}{lccc}
\hline Extract or standard drug & $\begin{array}{c}\text { DPPH scavenging activity } \\
\left(\mathrm{IC}_{50} \text { in } \mu \mathrm{g} / \mathrm{mL}\right)\end{array}$ & $\begin{array}{c}\text { Total antioxidant capacity } \\
\text { (g AAE/100g) }\end{array}$ & $\begin{array}{c}\text { Total phenolic content } \\
(\mathrm{g} \text { GAE/100g) }\end{array}$ \\
\hline Cassia nodosa & $78.71 \pm 6.84$ & $48.49 \pm 5.24$ & $28.48 \pm 3.13$ \\
Ascorbic acid & $20.71 \pm 2.39$ & NA & NA \\
\hline
\end{tabular}

Results were expressed as mean \pm SEM of 3 replicate experiments; NA, not applicable (test was not performed for that assay).
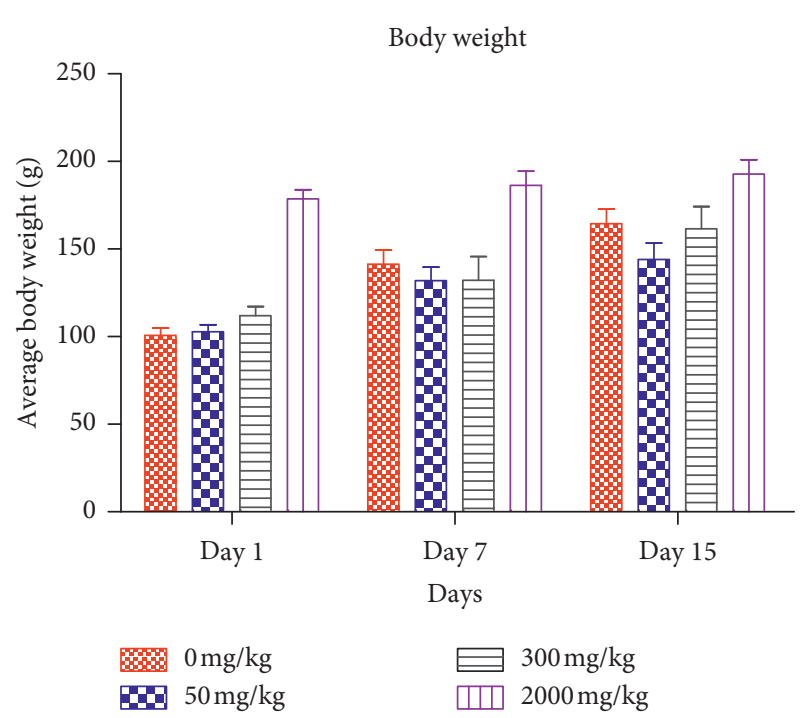

Figure 3: Average body weight of rats treated with C. nodosa extracts in acute toxicity study. Each bar represents mean \pm SEM $(n=5)$.

This is similar to the yields of ethanolic extracts obtained from medicinal plants [9]. Biological activities of most medicinal plants are as a result of the presence of secondary metabolites. These secondary metabolites have been implicated in the anticarcinogenic, antileprosy, antioxidant, antidiabetic, anti-inflammatory, anticholinergic, hypoglycemic, antimalarial, and antimicrobial activities of many medicinal plant extracts [31]. From the phytochemical screening, the ethanolic extract of Cassia nodosa stem bark was found to contain tannins, which are known to have impressive biological properties and are widely used in wound healing formulations [14]. Alkaloids were also present in the extract. Alkaloids have been found useful in the treatment of malaria, neuralgia, rheumatism, and hypertension. Also, alkaloids can be used to reduce abdominal pains, boils, septic wounds, eye conditions, and headaches by acting as analgesics [32]. Glycosides have been proven to be useful as emetics and diuretics [33]. Steroids can be used during pregnancy to enhance easy delivery and improve libido in men and fertility in women [34]. The crude extract was positive for the presence of both sterols and glycosides. Coumarins, which were also present in the Cassia nodosa extract, are known to exhibit anti-inflammatory and antimicrobial activities [35].

To evaluate the biological activity of the ethanolic extract of Cassia nodosa, 3 major classes of assays were used: antiplasmodial, antioxidant, and anti-inflammatory activities. These assays were chosen to reflect the traditional use of the plant. Thus, in vitro-based assays were used to evaluate antioxidant and antiplasmodial activities, whilst the in vivo-based carrageenan-induced edema in the chick model was used to assess anti-inflammatory activity.

The in vitro antiplasmodial activity of the Cassia nodosa extract was studied by testing it against chloroquine-sensitive (3D7) Plasmodium falciparum, a parasite strain commonly used in antiplasmodial drug sensitivity research. Microscopy was then employed in quantification of the percentage inhibition. The result from the study showed that the plant has an antiplasmodial activity with an $\mathrm{IC}_{50}$ value of $23.98 \mu \mathrm{g} / \mathrm{ml}$. The plant was thus considered to possess moderate antiplasmodial activity [30]. The results of this study show that Cassia nodosa has comparable antiplasmodial activity to other plant extracts such as Bidens pilosa, Paspalum scrobiculatum, and Mitragyna ciliata [9]. All these plants possessed moderate antiplasmodial activity against a chloroquine-sensitive Plasmodium falciparum strain. It has been reported that chloroform extracts of the stem bark and fruit pod of Cassia fistula also possessed moderate antiplasmodial activity [36]. Interestingly, other plant species in the genus Cassia have been validated as possessing antiplasmodial activities. Cassia siamea [37], Cassia occidentalis [38], Cassia nigricans [39], Cassia singueana, [40] and Cassia alata [41] have all been validated as possessing promising antiplasmodial activities. For some of these plants, some compounds responsible for the antiplasmodial activities have been isolated [42]. As shown in Figure 1, artemisinin (P) was able to completely clear all Plasmodium parasites from the infected red blood cells after 72 hours of treatment. In contrast, the negative solvent control clearly showed the presence of parasites in the red blood cells. In the Cassia nodosa treatment, most of the parasites were cleared, confirming the antiplasmodial activity recorded. No injury to red blood cells was also observed. This study thus provides scientific support for the antiplasmodial capabilities of the stem bark of Cassia nodosa.

In screening new anti-inflammatory drugs, carrageeninduced acute foot edema in animal models is commonly used $[8,22]$. The main action of anti-inflammatory agents is to block the activity of cyclooxygenase (COX) enzymes and reduce the production of prostaglandins (PG). Cytokines, chemokines, and eicosanoids (such as PG) are inflammatory mediators that stimulate inflammatory response during tissue damage [37, 39]. The extract of Cassia nodosa exhibited dose-dependent anti-inflammatory activities in this study by reducing the induced edema. The development of edema is biphasic. The first phase is attributable to the 


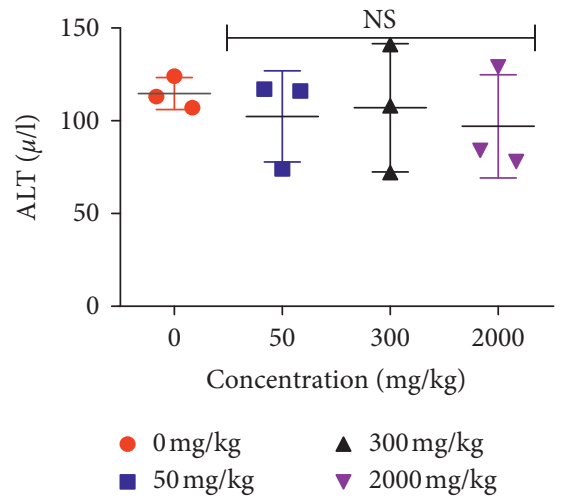

(a)

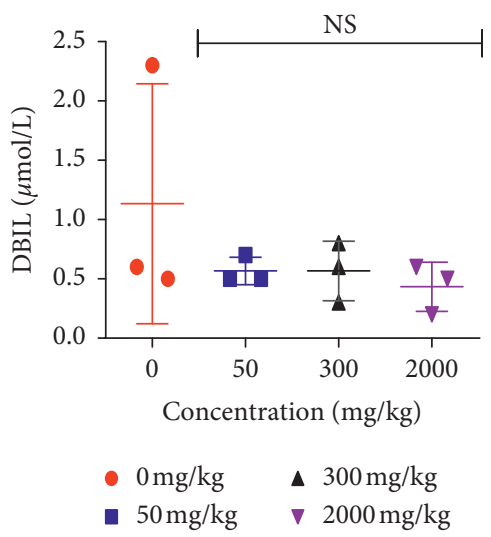

(d)

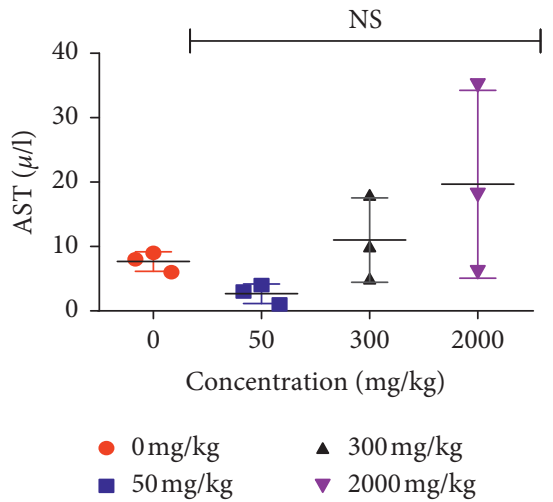

(b)

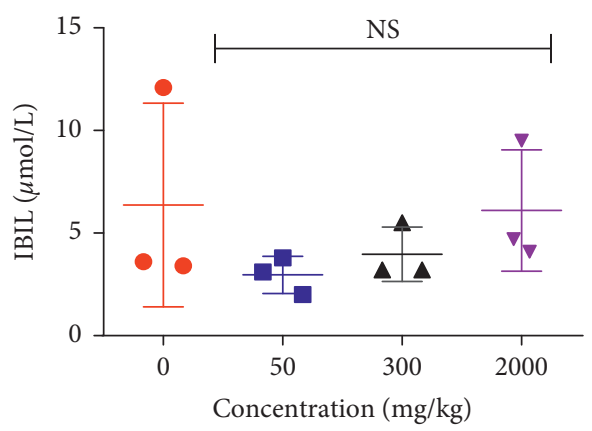

$$
\begin{array}{ll}
\text { - } 0 \mathrm{mg} / \mathrm{kg} & \text { \ } 300 \mathrm{mg} / \mathrm{kg} \\
\text { - } 50 \mathrm{mg} / \mathrm{kg} & \text { - } 200 \mathrm{mg} / \mathrm{kg}
\end{array}
$$

(e)

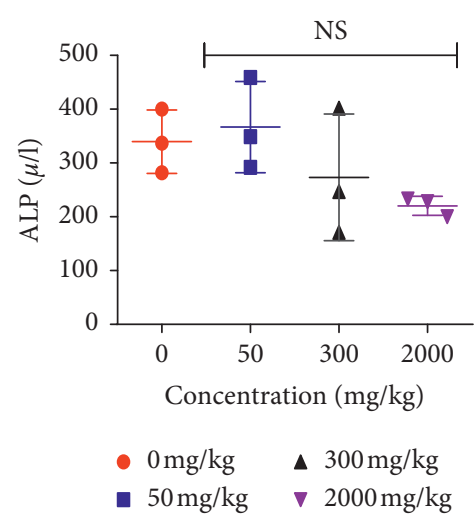

(c)

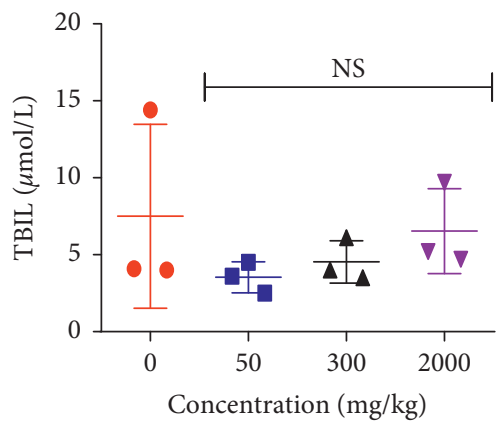

$$
\begin{array}{ll}
\text { - } 0 \mathrm{mg} / \mathrm{kg} & \multicolumn{1}{c}{300 \mathrm{mg} / \mathrm{kg}} \\
\text { - } 50 \mathrm{mg} / \mathrm{kg} & \boldsymbol{\nabla} 2000 \mathrm{mg} / \mathrm{kg}
\end{array}
$$

(f)

FIGURE 4: Scatter plot showing effect of C. nodosa extract on some key liver parameters: (a) alanine aminotransferase (ALT); (b) aspartate aminotransferase (AST); (c) alkaline phosphatase (ALP); (d) direct bilirubin (DB); (e) indirect bilirubin (IB); (f) total bilirubin (TB). Sample size for each treatment is $3(n=3) . P<0.05$ was considered to be statistically significant (one-way analysis of variance (ANOVA) followed by Dunnett's post hoc test).

release of kinins, histamine, and serotonin in the first 60 minutes after the injection of carrageenan. The second phase which is more pronounced is related to the release of PG within 2-3 hours [43]. Although this study did not explore the principal mechanism by which the extracts inhibited carrageen-induced inflammation, the possible anti-inflammatory activity of Cassia nodosa extract may be due to inhibitory effect on release of inflammation mediators since a rapid reduction in edema was observed upon extract administration. The low $\mathrm{ED}_{50}$ of the Cassia nodosa extract was comparable to the diclofenac used in this study. This result points to the presence of promising anti-inflammatory agent(s) in the extract which could be isolated. In crude extracts, active principles may work in synergy to elicit the desired response [44]. Even though the high activity of the extract in reducing inflammation may be attributed to single component in the mixture, it is also possible the synergistic action may play an important role in the observed antiinflammatory activity [45].

Cassia nodosa is traditionally used to treat many diseases whose pathogenesis is linked to oxidative stress. The antioxidant activities of the leaf extract of Cassia nodosa have been reported [46]. The ability of the stem bark extract to scavenge free radicals is however absent in the literature.
This study reported the antioxidant potentials of Cassia nodosa stem bark extract. The total antioxidant capacity was determined to be $48.49 \pm 5.24 \mathrm{gAAE} / 100 \mathrm{~g}$ crude extract. This indicates that the extracts of antioxidant potential are about half that of standard ascorbic acid. This is very impressive given that only the crude extract was evaluated. About $78 \mu \mathrm{g} / \mathrm{mL}$ of the extract was needed to scavenge $50 \%$ of DPPH radicals in the radical scavenging assay. Polyphenolic constituents have been associated with high radical scavenging capabilities. Detection of tannins in the extract and the presence of kaempferol derivatives in the plant support the antioxidant properties of the Cassia nodosa extract [46]. The high TPC value determined in the extracts supports the suggestion that antioxidant activity may be due to phenolic compounds present and could explain the traditional use of the plant to cure oxidative-based diseases.

To determine the safety of drugs and medicinal plant products for human use, a toxicological assessment is conducted to predict toxicity and provide guidelines for the selection of a "safe" dose [47]. Changes in body weight during treatment provide an index of the animal general health status, which may be important for assessing their health [48]. The body weight of all animals increased gradually throughout the duration of the study (Figure 3). 


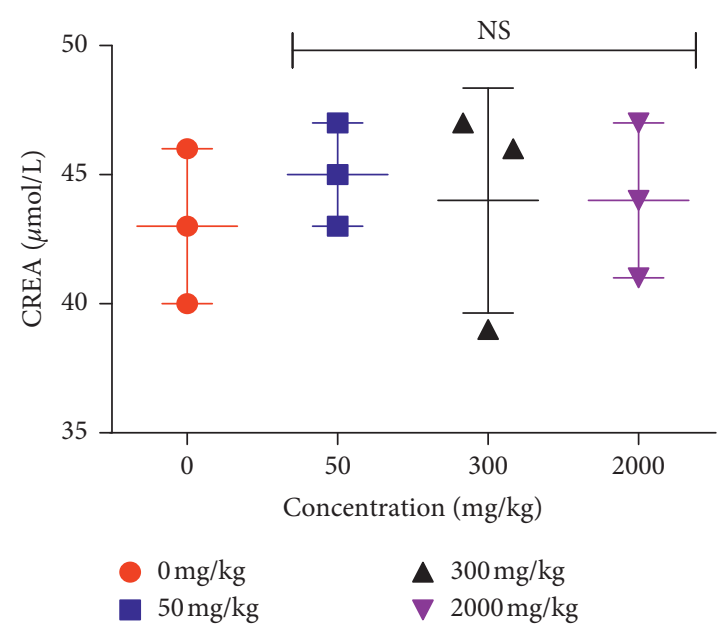

(a)

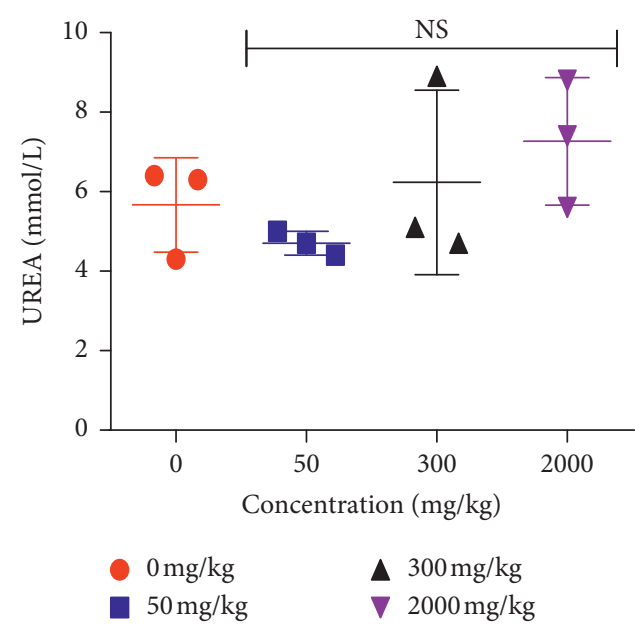

(b)

FIGURE 5: Scatter plots showing the effect of C. nodosa extract on some key kidney parameters: (a) creatinine; (b) urea. Sample size for each treatment is $3(n=3) . P<0.05$ was considered to be statistically significant (one-way analysis of variance (ANOVA) followed by Dunnett's post hoc test).

The average weight gain for the control rats was $43.75 \mathrm{~g}$. Average weights of rats administered with $50 \mathrm{mg} / \mathrm{kg}$, $300 \mathrm{mg} / \mathrm{kg}$, and $2000 \mathrm{mg} / \mathrm{kg}$ doses were $49.42 \mathrm{~g}, 40.13 \mathrm{~g}$, and $29.68 \mathrm{~g}$ respectively. These study results are in agreement with the results of Loha and coworkers, where a methanol extract of Syzygium guineense leaves were evaluated for their effects on body weights of rats [29]. The mean weight increase recorded in the Loha work is comparable to those observed in this study. Since clinical observations did not show any significant differences between treated groups and control, Cassia nodosa stem bark extract was nontoxic at doses at or below $2000 \mathrm{mg} / \mathrm{kg}$. Cassia nodosa ethanolic extract showed no mortality even at an oral dose of $2000 \mathrm{mg}$ per kg body weight in the female Wistar rats. Therefore, the median acute lethal dose value $\left(\mathrm{LD}_{50}\right)$ is more than $2000 \mathrm{mg}$ / $\mathrm{kg}$ [49].

Disease or response to toxic substances can be indicated by changes in key biochemical parameters which are sensitive indicators of metabolic defects or organ function. Detoxification and metabolism of compounds are the main function of the liver. The liver is thus a specific target organ for drugs and toxic substances. Biochemical assessment is important as there are several reports of kidney and liver toxicity associated with phytotherapeutic agents [50]. Alkaline phosphatase (ALP), aspartate aminotransferase (AST), and alanine aminotransferase (ALT) are important liver enzymes that serve as key indicators of liver damage [51]. Abnormal elevation of the liver enzymes is usually associated with liver damage or alteration in bile flow. When a liver cell is damaged, these enzymes leak into the blood and thus raise the enzyme level in the blood [52]. Total serum bilirubin may also be used to detect liver damage in addition to ALT, ASP, and AST. Bilirubin is a pigmented compound produced when macrophages degrade heme from aged red blood cells. Globin and iron from hemoglobin are recycled, and the unconjugated bilirubin (water insoluble and indirect reacting) circulates to the liver bound to albumin. Elevated bilirubin is a sign of liver cell damage. When the liver cell is unable to conjugate bilirubin, there is gradual increase in the serum levels of unconjugated bilirubin in the blood and this is a sign that there is liver function impairment [51].

In preclinical toxicity assessments, kidney biochemical changes are particularly liable to occur because of the fact that the kidneys eliminate many drugs and their metabolites. In this study, urea and creatinine assessment were critical as markers of kidney function. Urea and creatinine are usually increased in acute and chronic renal diseases. Diseased kidneys are unable to clear urea and creatinine, and as a result, urea and creatinine tend to accumulate and tend to be at high level in the sera of the blood [52,53]. After 14 days of treatment with Cassia nodosa extract, changes in biochemical parameters between the control and treatment groups up to a dose of $2000 \mathrm{mg} / \mathrm{kg}$ were statistically insignificant (Figure 5). This indicates that there were no significant changes in serum levels of both enzyme and nonenzyme parameters (total bilirubin, indirect bilirubin, direct bilirubin, ALP, ALT, AST, urea, and creatinine), verifying the nontoxic nature of Cassia nodosa extract at these concentrations. The results are similar to another study where these parameters (total bilirubin, ALP, ALT, and AST) were not significantly elevated in mice fed orally with methanolic seed extract of Cassia fistula at single high dose of $5,000 \mathrm{mg} / \mathrm{kg}$ [55].

\section{Conclusion}

The findings in this study showed that stem bark extract of Cassia nodosa does possess antiplasmodial, antioxidant, and anti-inflammatory activities. Phytochemicals such as glycosides, coumarins, alkaloids, tannins, and sterols were detected in the plant extract and may be responsible for these activities. Toxicological evaluation of the extract revealed no significant effect on the body weight of the rats used in the study. Additionally, no mortalities or adverse clinical 
manifestations were recorded. The biochemical data for the renal and hepatic function tests were similar for both control and treatment groups and indicate that Cassia nodosa extracts are safe at the concentrations tested. This study provides valuable scientific credence for the safety and efficacy of Cassia nodosa extracts in traditional herbal medicine. Isolation of the active principles responsible for the biological activities will provide useful compounds for potential use in drug discovery programs.

\section{Data Availability}

All data generated or analyzed during this study are included in this published article.

\section{Ethical Approval}

The project proposal and procedures were reviewed and approved by the Institution Ethics Review Board for Animal Use at the Kwame Nkrumah University of Science and Technology, Kumasi, Ghana.

\section{Conflicts of Interest}

The authors declare that there are no conflicts of interest.

\section{Authors' Contributions}

LSB, GA, and MKL conceived the study. All experiments were designed by LSB, MKL, and GA. Plant materials were collected by GA and MKL. MKL carried out the antiplasmodial work. Phytochemical screening, inflammation, toxicity, and antioxidant works were done by GA. Data analysis was by MKL, GA, and LSB. Manuscript was prepared by LSB, MKL, and GA. All authors read and approved the final manuscript.

\section{Acknowledgments}

The authors acknowledge the Department of Chemistry, Department of Pharmacology, and the Central Laboratory of the Kwame Nkrumah University of Science and Technology, Kumasi, and the Department of Immunology, Noguchi Memorial Institute for Medical Research (NMIMR), University of Ghana, Legon, for the use of their facilities for this study. Funding for this work was provided by the International Foundation for Science (IFS) Collaborative Research Grant to LSB.

\section{References}

[1] A. Mastinu, M. Premoli, G. Ferrari-Toninelli et al., "Cannabinoids in health and disease: Pharmacological potential in metabolic syndrome and neuroinflammation," Hormone molecular biology and clinical investigation, vol. 36, no. 2, Article ID 20180013, 2018.

[2] K. Karunamoorthi, K. Jegajeevanram, J. Vijayalakshmi, and E. Mengistie, "Traditional medicinal plants," Journal of Evidence-Based Complementary \& Alternative Medicine, vol. 18, no. 1, pp. 67-74, 2013.
[3] A. J. Medcalf, S. Bhattacharya, H. Momen, M. A. Saavedra, and M. Jones, Health for All: The Journey to Universal Health Coverage, Orient Blackswan, Hyderabad, New Delhi, India, 2015.

[4] M. Ekor, O. A. Osonuga, A. O. Odewabi, A. G. Bakre, and K. S. Oritogun, "Toxicity evaluation of yoyo "cleanser" bitters and fields Swedish bitters herbal preparations following subchronic administration in rats," American Journal of Pharmacology and Toxicology, vol. 5, no. 4, pp. 159-166, 2010.

[5] C. Liu, H. Fan, Y. Li, and X. Xiao, "Research advances on hepatotoxicity of herbal medicines in China," BioMed Research International, vol. 2016, 2016.

[6] T. van Andel, B. Myren, and S. van Onselen, "Ghana's herbal market," Journal of Ethnopharmacology, vol. 140, no. 2, pp. 368-378, 2012.

[7] K. S. Appiah, C. P. Oppong, H. K. Mardani et al., "Medicinal plants used in the Ejisu-Juaben Municipality, Southern Ghana: an ethnobotanical study," Medicines, vol. 6, no. 1, p. 1, 2019.

[8] E. Woode, C. Ansah, G. K. Ainooson, W. M. Abotsi, A. Y. Mensah, and M. Duweijua, "Anti-inflammatory and antioxidant properties of the root extract of Carissa edulis (Forsk.) Vahl (Apocynaceae)," The Journal of Science and Technology, vol. 27, no. 3, pp. 5-15, 2007.

[9] M. K. Laryea and L. S. Borquaye, "Antimalarial efficacy and toxicological assessment of extracts of some ghanaian medicinal plants," Journal of Parasitology Research, vol. 27, 2019.

[10] N. L. Lartey, H. Asare-Anane, E. K. Ofori et al., "Antidiabetic activity of aqueous stem bark extract of Annickia polycarpa in alloxan-induced diabetic mice," Journal of Traditional and Complementary Medicine, vol. 2, 2020.

[11] L. S. Borquaye, M. S. Doetse, S. O. Baah, and J. A. Mensah, "Anti-inflammatory and anti-oxidant activities of ethanolic extracts of Tamarindus indica L. (Fabaceae)," Cogent Chemistry, vol. 6, no. 1, 2020.

[12] P. Acevedo-Rodríguez and M. T. Strong, Catalogue of Seed Plants of the West Indies, Smithsonian Contributions to Botany, New York, NY, USA, 2012.

[13] R. Broome, K. Sabir, and S. Carrington, Plants of the Eastern Caribbean. Online Database, University of the West Indies, Barbados, 2007.

[14] H. A. Mohammed, M. M. Abdel-Aziz, and M. M. Hegazy, "Anti-oral pathogens of Tecoma stans (L.) and Cassia javanica (L.) flower volatile oils in comparison with chlorhexidine in accordance with their folk medicinal uses," Medicina, vol. 55, no. 6, p. 301, 2019.

[15] J. P. Mehta, P. H. Parmar, S. H. Vadia, M. K. Patel, and C. B. Tripathi, "In-vitro antioxidant and in-vivo anti-inflammatory activities of aerial parts of Cassia species," Arabian Journal of Chemistry, vol. 10, pp. S1654-S1662, 2017.

[16] W. C. Evans, Trease and Evans Pharmacognosy, International Edition E-Book. Elsevier Health Sciences, Berlin, Germany, 2009.

[17] A. Sofowora, Screening Plants for Bioactive Agents, Spectra Books Ltd Sunshine House Ib, Niger, USA, 2nd edition, 1993.

[18] A. G. Maier and M. Rug, In Vitro Culturing Plasmodium Falciparum Erythrocytic Stages, Springer, Berlin, Germany, 2012.

[19] S. Ravikumar, S. Jacob Inbaneson, P. Suganthi, M. Venkatesan, and A. Ramu, "Mangrove plants as a source of lead compounds for the development of new antiplasmodial drugs from South East coast of India," Parasitology Research, vol. 108, no. 6, pp. 1405-1410, 2011. 
[20] P. J. Waako, E. Katuura, P. Smith, and P. Folb, "East African medicinal plants as a source of lead compounds for the development of new antimalarial drugs," African Journal of Ecology, vol. 45, no. 1, pp. 102-106, 2007.

[21] L. S. Borquaye, G. Darko, M. K. Laryea, V. Roberts, R. Boateng, and E. N. Gasu, "Anti-inflammatory activities of extracts from Oliva sp., Patella rustica, and Littorina littorea collected from Ghana's coastal shorelines," Cogent Biology, vol. 3, no. 1, 2017.

[22] S. Ofori-Baah and L. S. Borquaye, "Ethanolic leaf extract from Strophanthus gratus (Hook.) Franch.(Apocynaceae) exhibits anti-inflammatory and antioxidant activities," Cogent Biology, vol. 3, 2019.

[23] J. N. Gyesi, R. Opoku, and L. S. Borquaye, "Chemical composition, total phenolic content, and antioxidant activities of the essential oils of the leaves and fruit pulp of Annona muricata L.(Soursop) from Ghana," Biochemistry Research Institute, vol. 2019, 2019.

[24] L. S. Borquaye, G. Darko, N. Oklu, C. Anson-Yevu, and A. Ababio, "Antimicrobial and antioxidant activities of ethyl acetate and methanol extracts of Littorina littorea and Galatea paradoxa," Cogent Chemistry, vol. 2, no. 1, 2016.

[25] OECD-420, Organization of Economic Co-operation and Development (OECD), "The OECD guideline for testing of chemicals: 420 acute oral toxicity-fixed dose procedures," OECD-420, Organization of Economic Co-operation and Development (OECD), vol. 14, 2001.

[26] OECD-425, "Acute oral toxicity-up-and-down-procedure (UDP)," OECD Guidelines for the Testing of Chemicals, vol. 425, no. 2, pp. 1-27, 2008.

[27] J. P. Dzoyem, B. Nkegoum, and V. Kuete, “A 4-week repeated oral dose toxicity study of the methanol extract from Diospyros canaliculata in rats," Comparative Clinical Pathology, vol. 22, no. 1, pp. 75-81, 2013.

[28] H. M. Nana, R. A. N. Ngane, J. R. Kuiate et al., "Acute and subacute toxicity of the methanolic extract of Pteleopsis hylodendron stem bark," Journal of Ethnopharmacology, vol. 137, no. 1, pp. 70-76, 2011.

[29] M. Loha, A. Mulu, S. M. Abay, W. Ergete, and B. Geleta, "Acute and subacute toxicity of methanol extract of Syzygium guineense leaves on the histology of the liver and kidney and biochemical compositions of blood in rats," Evidence-Based Complementary and Alternative Medicine, vol. 2019, 2019.

[30] V. Ramanandraibe, P. Grellier, M.-T. Martin et al., "Antiplasmodial phenolic compounds from piptadenia pervillei," Planta Medica, vol. 74, no. 4, pp. 417-421, 2008.

[31] J. A. Shazhni, A. Renu, and P. Vijayaraghavan, "Insights of antidiabetic, anti-inflammatory and hepatoprotective properties of antimicrobial secondary metabolites of corm extract from Caladium $\times$ hortulanum," Saudi Journal of Biological Sciences, vol. 25, no. 8, pp. 1755-1761, 2018.

[32] R. A. DeFilipps and G. A. Krupnick, "The medicinal plants of Myanmar," PhytoKeys, vol. 102, p. 1, 2018.

[33] V. Kuete, "Mutagenicity and carcinogenicity of African medicinal plants," in Toxicological Survey of African Medicinal Plants, pp. 277-322, Elsevier, London, UK, 2014.

[34] S. La Vignera, R. A. Condorelli, R. Cannarella, Y. Duca, and A. E. Calogero, "Sport, doping and female fertility," Reproductive Biology and Endocrinology, vol. 16, no. 1, p. 108, 2018.

[35] R. Bhuvaneswari and R. Gobalakrishnan, "Antimicrobial potential and structural elucidation of bioactive compounds from flower extract of Cassia javanica L." Indian Journal of Natural Products and Resources (IJNPR) [Formerly Natural Product Radiance (NPR)], vol. 5, no. 1, pp. 34-39, 2015.
[36] M. H. Grace, C. Lategan, R. Graziose, P. J. Smith, I. Raskin, and M. A. Lila, "Antiplasmodial activity of the ethnobotanical plant Cassia fistula," Natural Product Communications, vol. 7, no. 10, 2012.

[37] H. Morita, S. Oshimi, Y. Hirasawa et al., "Cassiarins A and B, novel antiplasmodial alkaloids from Cassia siamea," Organic Letters, vol. 9, no. 18, pp. 3691-3693, 2007.

[38] L. Tona, R. K. Cimanga, K. Mesia et al., "In vitro antiplasmodial activity of extracts and fractions from seven medicinal plants used in the Democratic Republic of Congo," Journal of Ethnopharmacology, vol. 93, no. 1, pp. 27-32, 2004.

[39] O. O. Obodozie, L. C. Okpako, F. D. Tarfa et al., "Antiplasmodial principles from Cassia nigricans," Pharmaceutical Biology, vol. 42, no. 8, pp. 626-628, 2005.

[40] B. Adzu, J. Abbah, H. Vongtau, and K. Gamaniel, "Studies on the use of Cassia singueana in malaria ethnopharmacy," Journal of Ethnopharmacology, vol. 88, no. 2, pp. 261-267, 2003.

[41] O. Da, "Evaluation of the antiplasmodial activity and lethality of the leaf extract of Cassia alata L.(Fabaceae)," Journal of Biological Sciences, vol. 19, no. 4, pp. 171-178, 2016.

[42] M. Eddouks, D. Chattopadhyay, and N. A. Zeggwagh, "Animal models as tools to investigate antidiabetic and anti-inflammatory plants," Evidence-Based Complementary and Alternative Medicine, vol. 2012, 2012.

[43] I. Posadas, M. Bucci, F. Roviezzo et al., "Carrageenan-induced mouse paw oedema is biphasic, age-weight dependent and displays differential nitric oxide cyclooxygenase-2 expression," British Journal of Pharmacology, vol. 142, no. 2, pp. 331-338, 2004.

[44] X. Zhou, S. W. Seto, D. Chang et al., "Synergistic effects of Chinese herbal medicine: a comprehensive Review of methodology and current research," Frontiers in Pharmacology, vol. 7, 2016.

[45] M. M. Abu-Serie, N. H. Habashy, and W. E. Attia, "In vitro evaluation of the synergistic antioxidant and anti-inflammatory activities of the combined extracts from Malaysian Ganoderma lucidum and Egyptian Chlorella vulgaris," BMC Complementary Medicine and Therapies, vol. 18, no. 1, pp. 1-13, 2018.

[46] A. Sharma, S. Ahmad, and S. L. Harikumar, "Pharmacognosy, phytochemistry \& pharmacology of Cassia javanica Linn," International Journal of Pharmaceutical Sciences Review and Research, vol. 3, no. 4, pp. 101-105, 2014.

[47] W. M. H. Al-Kadmi, Acute Toxicity, Antioxidant and Wound Healing Potential of Ethanolic Extract of Goniothalamus Umbrosus in rats/Wasan MJ Hussain Al-Kadmi, University of Malaya, Kuala Lumpur, Malaysia, 2012.

[48] S. Sharma, K. Sharma, O. Yadav, and K. P. Sharma, "Alterations in biochemical and histopathological profile of liver in distillery soil leachate treated Swiss albino Mice Musculus L." Pharmacologyonline, vol. 3, pp. 1047-1053, 2009.

[49] OECD, "Test no. 423: acute oral toxicity-acute toxic class method," OECD Guidelines for the Testing of Chemicals, vol. 3, pp. 1-14, 2002.

[50] S. Subramanya, B. Venkataraman, M. Meeran, S. Goyal, C. Patil, and S. Ojha, "Therapeutic potential of plants and plant derived phytochemicals against acetaminophen-induced liver injury," International Journal of Molecular Sciences, vol. 19, no. 12, p. 3776, 2018.

[51] S. K. Ramaiah, "A toxicologist guide to the diagnostic interpretation of hepatic biochemical parameters," Food and Chemical Toxicology, vol. 45, no. 9, pp. 1551-1557, 2007. 
[52] C. A. O. Féres, R. C. Madalosso, O. A. Rocha et al., "Acute and chronic toxicological studies of Dimorphandra mollis in experimental animals," Journal of Ethnopharmacology, vol. 108, no. 3, pp. 450-456, 2006.

[53] A. Gianoncelli, S. A. Bonini, M. Bertuzzi et al., "An integrated approach for a structural and functional evaluation of biosimilars: implications for erythropoietin," BioDrugs, vol. 29, no. 4, pp. 285-300, 2015.

[54] S. L. Jothy, Z. Zakaria, Y. Chen, Y. L. Lau, L. Y. Latha, and S. Sasidharan, "Acute oral toxicity of methanolic seed extract of Cassia fistula in mice," Molecules, vol. 16, no. 6, pp. 5268-5282, 2011. 